\title{
PSICOLOGIA DA EDUCAÇÃO: ANÁLISE DO ESTATUTO ESPISTEMOLÓGICO
}

\section{Psychology of education: analysis of the spistemological status}

\author{
Rodrigo Regert - SENAC(Videira/SC) / Brasil \\ Adelcio Machado dos Santos - UNIARP(Caçador/SC) / Brasil
}

\begin{abstract}
RESUMO: A Psicologia consiste na Ciência Humana devotada à persecução de recursos os quais possibilitem a compreensão do homem através de seu comportamento, facilitando, assim, a convivência consigo mesmo e com o outro. Ela se diferencia das demais ciências humanas por ter como objeto o estudo da subjetividade: é esse seu modo particular, específico de contribuição para a compreensão da totalidade da vida humana. A Psicologia da Educação é um dos ramos da Psicologia voltado estritamente ao estudo de problemas psíquicos relacionados à educação, em especial, problemas de aprendizagem, motivação e ajustamento escolar. Visa, precipuamente, a compreender e aperfeiçoar os fenômenos de ensino e aprendizagem. Diante disso, o presente artigo tem como objetivo verificar a importância que a Psicologia da Educação tem durante os problemas no fenômeno da aprendizagem. Para esse fim, nos aspectos metodológicos foi utilizada natureza básica, abordagem qualitativa, sendo caracterizada como pesquisa exploratória e bibliográfica. Concluiu-se que a Psicologia da Educação tem contribuído de forma efetiva na renovação dos métodos de ensino, na modificação das formas de aprendizagem e nos objetivos educacionais e, para que o educador possa compreender o desenvolvimento do processo de aprendizagem no educando, é de fundamental importância que ele tenha uma formação adequada na área da Psicologia da Educação. Somente com base nos conhecimentos sobre a maneira como se desenvolve a aprendizagem é que o educador poderá compreender o educando nas situações de dificuldade. Por fim, para tornar-se um educador especialista e eficiente requer tempo e experiência.
\end{abstract}

Palavras-chave: Aprendizagm. Educação. Psicologia.

ABSTRACT: Psychology is the Human Science devoted to the pursuit of resources which enable the understanding of man through his behavior, thus facilitating coexistence with himself and with others. It differs from other humanities by having as its object the study of subjectivity: this is its particular, specific way of contributing to comprehension of the totality of human life. Educational Psychology is one of the branches of Psychology strictly focused on the study of psychic problems related to education, in particular, learning problems, motivation and school adjustment. It primarily aims to understand and improve the phenomena of teaching and learning. Therefore, this article aims to verify the importance that Educational Psychology has during problems in the learning phenomenon. For this purpose, in the methodological aspects, basic nature and qualitative approach were used, being characterized as an exploratory and bibliographical research. It was concluded that Educational Psychology has been effectively contributing to the renewal of teaching methods, the modification of learning forms and educational objectives and, for the educator to understand the development of the student's learning process, it is of fundamental importance that he has adequate training in the area of Educational Psychology. Only on the basis of knowledge about the way learning develops 
can the educator understand the student in difficult situations. Finally, becoming an expert and efficient educator requires time and experience.

Keywords: Education. Learning. Psychology.

\section{INTRODUÇÃO}

A palavra psicologia deriva de dois termos gregos, a saber: psiqué, que significa "expiração, alma, vida"; e logia, termo derivado de logos que significa "estudo de, tratado a respeito". Assim, num sentido etimológico, a psicologia seria o estudo da alma ou a ciência da alma, confundindo-se com a própria história da Filosofia (MAYER, 2001).

As especulações em torno da natureza humana iniciaram-se na Grécia Antiga, por meio dos filósofos. Acreditavam eles que todo ser humano possuía uma contraparte imaterial do corpo, de onde provinha os processos psíquicos, dos quais o cérebro seria apenas mediador. Durante séculos, foi como estudo da alma que a Psicologia existiu (CRUZ, 2013).

A Psicologia, propriamente dita, tomou forma como disciplina autônoma e independente da Filosofia apenas no ano de 1879, por meio da criação efetuada por Wundt do primeiro laboratório exclusivamente dedicado aos estudos psíquicos (TOURINHO; NETO; NENO, 2004).

Deste modo, a Psicologia passa a ser considerada como ciência, pelo simples fato de os cientistas a ela se dedicarem experimentalmente. Mas é importante ressaltar que, apesar de ser considerada ciência, a psicologia nem sempre tem condições de fazer uso das técnicas experimentais das Ciências Exatas e da Terra.

Já no início do século XX, emergiram várias escolas psíquicas que sucederam umas às outras dando origem às visões que atualmente predominam nas investigações psicológicas. Entre essas escolas pode-se citar: estruturalismo, funcionalismo, behaviorismo, gestaltismo e psicanálise. Com isso, desenvolveu-se o campo próprio de estudo da Psicologia.

De acordo com Teles (1999), a Psicologia procura buscar recursos que propiciem a compreensão do homem por meio de seu comportamento, para facilitar a convivência consigo mesmo e com o outro. Em outras palavras, a Psicologia pretende fornecer ao 
indivíduo os subsídios necessários para que ele saiba lidar consigo e com as experiências que a vida que proporciona.

Para Bock (et al. 2002), o que diferencia a psicologia dos demais ramos das ciências humanas, uma vez que cada um desses ramos enfoca o homem de modo particular, é o estudo da subjetividade: é esse seu modo particular, específico de contribuição para a compreensão da totalidade da vida humana. Essa subjetividade humana se expressa por meio de seu comportamento.

O comportamento não envolve somente as reações externas que a pessoa expõe, mas também as atividades da consciência, e mesmo do inconsciente, num plano indiretamente observável. Teles (1999) ainda acrescenta que, como estudo científico do comportamento, a psicologia deve procurar alcançar três objetivos principais, quais sejam: a descrição, a predição e o controle do comportamento.

Dentro da Psicologia, podem ser identificadas várias áreas específicas que se voltam para o estudo de um determinado contexto. Entre estas áreas situa-se a Psicologia da Educação, objeto do presente estudo, que tem como objetivo verificar a importância que a Psicologia da Educação tem durante os problemas no fenômeno da aprendizagem.

Para esse fim, nos aspectos metodológicos dessa pesquisa, foi utilizada a natureza básica, uma vez que não houve a intenção de aplicá-la, sua abordagem foi qualitativa, sendo caracterizada como exploratória e bibliográfica.

Visando atender ao objetivo proposto, o artigo se desdobrou em quatro momentos importantes. No primeiro, foi discutido o conceito da Psicologia da Educação. No segundo, as Contribuições Psicológicas ao Ensino. No terceiro, a Aprendizagem na Perspectiva da Psicologia da Educação; e, por último, a Psicologia da Educação na Formação do Educador.

\section{O CONCEITO DA PSICOLOGIA DA EDUCAÇÃO}

Desde que a Psicologia adquiriu estatuto epistemológico, no umbral do século $\mathrm{XX}$, verificam-se discussões sobre o que ela realmente estuda e qual a forma que utiliza para desenvolver seus estudos (HOLANDA, 2018).

Alguns pesquisadores defendem que a Psicologia da Educação é simplesmente o conhecimento obtido na Psicologia Geral e aplicado às atividades de sala de aula. Outros 
especialistas acreditam que ela envolve a aplicação dos métodos da Psicologia ao estudo da vida nas salas de aulas e nas escolas.

A Psicologia da Educação consiste na área da Psicologia que se devota ao perlustre de problemas psíquicos relacionados à educação, em especial, problemas de aprendizagem, motivação e ajustamento escolar. Na área da aprendizagem, a atuação do psicólogo é desenvolvida para propiciar a avaliação dos diferentes métodos de ensino, programas e efeitos de inovações educacionais, além de elaborar testes e medidas de rendimento escolar (ZUCOLOTTO, 2018).

Ademais, conforme Alencar (1983), o psicólogo dessa área também pode se dedicar à elaboração de procedimentos a serem utilizados com alunos que apresentam retardo mental, problemas emocionais ou dificuldades em áreas específicas, como a leitura e as escritas.

Seguindo esse entendimento, Woolfolk (2000) também assegura que a Psicologia da Educação tem como principal objetivo compreender e aperfeiçoar os processos de ensino e aprendizagem. Os psicólogos da educação desenvolvem conhecimento e métodos, mas ao mesmo tempo fazem uso dos conhecimentos e métodos que são próprios da psicologia ou de outras disciplinas relacionadas para estudar a aprendizagem e o ensino nas situações que se levantam no cotidiano escolar.

Decompondo-se o objetivo geral da psicologia da educação, Fontoura (1973) afirma que a psicologia serve à educação de quatro modos: 1) contribui para a melhor compreensão das aspirações da educação, definindo-as e limitando-as; 2) auxilia a apreciar a probabilidade de que uma aspiração seja exeqüível; 3) contribui para o conhecimento dos métodos de ensino, tornado-os mais eficientes e obtendo maior rendimento escolar, uma vez que possibilita obter o conhecimento da natureza humana, seus fenômenos e suas leis; 4) indica os meios para a averiguação das funções intelectuais, estabelecendo com isso as diferenças individuais e grupando os indivíduos segundo tipos psicológicos.

Assim, a visão que prevalece na psicologia da educação é que ela, além de fazer uso dos conhecimentos que derivam da psicologia geral, também desenvolveu suas próprias teorias, seus próprios métodos de pesquisa, problemas e técnicas. Os psicólogos da educação estudam o que as pessoas pensam e fazem quando ensinam e aprendem em 
um círculo específico, em um ambiente específico, no qual a educação e o treinamento devem acontecer, sustenta Berliner (apud WOOLFOLK, 2000).

A condução de pesquisas para testar possíveis respostas é uma das principais tarefas da psicologia da educação. A outra é procurar combinar os resultados de vários estudos em teorias que busquem apresentar uma visão unificada de fatos como o ensino, a aprendizagem e o desenvolvimento. Os psicólogos da educação criam e conduzem diferentes tipos de pesquisas diferentes em suas tentativas de compreender o ensino e a aprendizagem.

Alguns destes estudos são as pesquisas descritivas, cujo objetivo consiste em simplesmente descrever eventos em uma turma em particular ou em diversas turmas. De acordo com Woolfolk (2000), em muitas situações, os resultados dos estudos descritivos incluem relatos de correlações. Uma correlação é um número que indica a força e a direção de uma relação entre dois eventos ou medidas. Quando se tem uma correlação positiva, os dois fatores relacionados aumentam ou diminuem juntos. À medida que um deles aumenta, o outro também aumenta. Já a correlação negativa significa que os aumentos em um fator estão relacionados à diminuição no outro.

Um segundo tipo de pesquisa desenvolvido é a experimentação, a qual permite que os psicólogos da educação se situem para além das predições e efetivamente estudem causas e efeitos. Em vez de apenas observarem e descreverem os eventos, os investigadores introduzem mudanças e registram os resultados. Muitas vezes costuma-se trabalhar em conjunto, utilizando, ao mesmo tempo, as pesquisas descritivas e experimentais.

A pesquisa é uma ferramenta primária utilizada para alcançar o objetivo da psicologia da educação, qual seja o de compreender o ensino e a aprendizagem. Porém, conforme Woolfolk (2000), alcançar este objetivo é um processo lento, visto que existem poucos estudos que respondem a uma pergunta de modo definitivo em decorrência da complexidade atrelada aos seres humanos.

\section{CONTRIBUIÇÕES PSICOLÓGICAS AO ENSINO}

A psicologia da educação tem contribuído de forma efetiva na renovação dos métodos de ensino, na modificação das formas de aprendizagem e nos objetivos 
educacionais. Entretanto, grande parte destas contribuições são entendidas e interpretadas superficialmente, o que acarreta problemas e dificuldades para os educadores.

Por outro lado, esquece-se de que qualquer contribuição sempre vem acompanhada de vantagens e desvantagens ao ensino, sendo que nem todas as inovações são aplicáveis a qualquer contexto escolar e que todas trazem consequências que devem ser previstas e assumidas, tanto por alunos como por educadores.

Deste modo, por exemplo, ao assumir-se a hipótese pedagógica de que todo indivíduo deseja aprender, criar e desenvolver, caso não seja favorecida a expansão e realização pessoal, não se conseguirá leva-lo à aprendizagem das opções, ao sentido da autodireção e da adaptação significativa.

Neste sentido, Novaes (1977) sustenta que há também uma preocupação exagerada com o modismo. Outro problema que a autora levanta é o radicalismo que invalida qualquer discussão e diálogo profícuo, como é o caso de serem considerados os seguidores de uma determinada escola psíquica únicos corretos ou detentores da verdade. Assim, é essencial relacionar a teoria com a prática educativa e, por conseguinte, à eficácia da ação educacional e à metodologia do ensino.

Para tanto é conveniente proceder-se uma análise comparativa entre as diferentes correntes psicológicas a fim de analisar como a divergência entre alguns pontos de vista, por vezes, invalida objetivos comuns, relacionando-se, assim, aspectos prioritários e fundamentais que darão uma visão ampla e abrangente do processo educativo. Tal análise é necessária uma vez que a educação visa o pleno desenvolvimento da personalidade humana num clima de respeito pelos direitos do homem e pelas suas liberdades fundamentais.

De acordo com Novaes (1977), quando se afirma que educar é auxiliar o indivíduo a se construir na sua autenticidade, organizando o mundo dentro de si, depreende-se que necessitará de todas as suas energias, forças e habilidade para integrá-las aos processos de aprendizagem e de adaptação. Por outro lado, como o processo educativo pretende promover a autonomia do indivíduo, as etapas e crises evolutivas necessitam ser levadas em consideração, no intento de atualizar as forças do próprio Eu, possibilitando ao indivíduo atingir a sua autodeterminação.

A proposta de Piaget (apud NOVAES, 1977) em relação às diversas etapas evolutivas contribui substancialmente para um melhor posicionamento dos métodos de 
ensino, pois reforça a importância para o desenvolvimento cognitivo da criança e de suas atividades espontâneas, objetivando o valor da organização intelectual e das situações que condicionem um certo número de associações motoras e verbais que irão facilitar a aquisição de novos conhecimentos.

Já Skinner (apud NOVAES, 1977), ao introduzir no processo do ensino os condicionamentos e as técnicas de reforço, justifica que cada pessoa tem um ritmo próprio para aprender que deve ser respeitado, podendo controlar a própria aprendizagem, desde que exista curiosidade e motivação. O reforço seria o próprio interesse ou o prazer de aprender a matéria, podendo o uso das máquinas e da tecnologia auxiliar o aluno na sua aprendizagem escolar.

Para este pesquisador, o ensino compreende a disposição das contingências de reforçamento que controlam o comportamento do aluno, devendo o educador ter conhecimento dos diversos tipos de recursos de ensino, a fim de deixar aberta a via à originalidade de cada indivíduo.

\section{A APRENDIZAGEM NA PERSPECTIVA DA PSICOLOGIA DA EDUCAÇÃO}

O termo aprender costuma ser utilizado sem dificuldades, uma vez que os indivíduos têm conhecimento de que este termo envolve a capacidade para se fazer algo do qual anteriormente não se tinha conhecimento de como era feito. Entretanto, para a psicologia em geral e para a psicologia educacional, o conceito de aprendizagem não constitui algo tão simples assim.

Existem diferentes modos de aprendizagem, isto é, há diversos fatores que conduzem o indivíduo a apresentar um comportamento que anteriormente não apresentava. Assim, a psicologia transforma a aprendizagem em um processo a ser investigado.

Para Teles (1974), a aprendizagem compreende um processo, ou seja, uma atividade interior, que inicia, tem seu desenvolvimento e atinge um fim. Como processo, é algo muito pessoal, mas que pode ser influenciado, com êxito, por pessoas habilitadas e pelo meio enriquecido de estímulos e técnicas. A criança é o indivíduo apto a desencadear este processo, a qualquer momento.

Já Falcão (1984) define a aprendizagem como uma modificação relativamente duradoura do comportamento, por meio de treino, experiência e observação. Caso o 
indivíduo tenha treinado ou passado por uma experiência especialmente significativa para ele, ou ainda tenha observado alguém realizando algo, e depois disso mostrou-se de alguma forma modificado, podendo demonstrar esta modificação desde que se apresentem condições adequadas, e, além disso, mantiver esta mudança por tempo razoavelmente longo, então se pode afirmar que houve aprendizagem.

Existe também uma série de fatores que podem influenciar no processo de aprendizado, dificultando-o. De acordo com Teles (1974), tensão, conflito, angústia e ansiedade são os fatores emocionais apontados como causadores de queda de rendimento escolar da criança, provocando distúrbios intelectuais e até mesmo físicos. Além disso, a carência afetiva, que decorre do abandono dos pais e da falta de amor também tem grande influência negativa na aprendizagem.

Conforme Piletti (1985), o processo de aprendizagem envolve sete etapas: motivação, objetivo, preparação ou prontidão, obstáculo, respostas, reforço, generalização.

A motivação é fundamental no processo de aprendizagem, pois sem ela a criança não aprende, por mais que o educador se esforce. Recompensas e punições não solucionam o problema caso o aluno não esteja motivado. Motivar alguém, sustenta Alencar (1983), implica levá-lo a agir ou a produzir uma resposta.

O objetivo, elemento que integra a aprendizagem, é a orientação do comportamento do indivíduo motivado para a satisfação de suas necessidades. A preparação ou prontidão refere-se ao momento exato em que o indivíduo está preparado ou capacitado para alcançar seus objetivos. Assim, muitas dificuldades escolares surgem em decorrência do fato de o aluno não estar devidamente preparado para as aprendizagens que lhe são propostas.

Os obstáculos são representados pelas barreiras impostas ao indivíduo para realizar a aprendizagem. Piletti (1985) sustenta que, se não houvesse obstáculos, barreiras, não haveria necessidade de aprendizagem, visto que bastaria o indivíduo repetir comportamentos anteriores. Esses obstáculos podem ser de natureza social, psicológica ou física.

A etapa da resposta envolve a ação efetuada pelo indivíduo em aprendizado de acordo com sua interpretação da situação, procurando a melhor maneira de vencer o 
obstáculo. Assim, por exemplo, a criança tentará dividir o tempo entre estudar e jogar bola.

A última etapa do aprendizado é a generalização que consiste em integrar a resposta correta ao repertório de conhecimentos. A generalização possibilita que o indivíduo dê a mesma resposta que o levou ao êxito diante de situações semelhantes. Com isso, a nova aprendizagem passa a integrar o indivíduo e vai ser utilizada sempre que for necessária.

Atualmente, existe um grande número de teorias de aprendizagem. Conforme Bock (et al. 2002), essas teorias podem ser genericamente reunidas em duas categorias: as teorias do condicionamento e as teorias cognitivistas. No primeiro grupo, estão as teorias que definem a aprendizagem pelas suas conseqüências comportamentais e enfatizam as condições ambientais como forças propulsoras da aprendizagem. Sob esta visão, a aprendizagem é a conexão entre o estímulo e a resposta.

No segundo grupo, situam-se as teorias que definem a aprendizagem como um processo de relação do sujeito com o mundo externo e que tem consequências no plano da organização interna do conhecimento (organização cognitiva). Nesta concepção, a aprendizagem compreende um elemento que provém de uma comunicação com o mundo e se acumula sob a forma de uma riqueza de conteúdos cognitivos.

De modo geral, podem ser apresentadas três controvérsias entre as teorias do condicionamento e as teorias cognitivistas, sustenta Bock (2002). A primeira delas referese à questão do que é aprendido e como. Para os teóricos do condicionamento, os indivíduos aprendem hábitos, ou seja, aprendem a associação entre um estímulo e uma resposta e aprendem praticando; para os cognitivistas, aprende-se a relação entre ideias (conceitos) e aprende-se abstraindo da própria experiência.

A segunda controvérsia diz respeito à questão do que mantém o comportamento que foi aprendido. Para os teóricos do condicionamento, o comportamento é mantido pelo sequenciamento de respostas. Já na visão dos psicólogos cognitivistas, o que mantém um comportamento são os processos cerebrais centrais, tais como a atenção e a memória, que são integradores dos comportamentos.

Quanto à terceira controvérsia, refere-se à maneira como cada indivíduo soluciona uma nova situação-problema (transferência de aprendizagem). Para os teóricos do condicionamento, os indivíduos evocam hábitos passados apropriados para o novo 
problema e responde, quer de acordo com os elementos que o problema novo tem em comum com outros já aprendidos, quer de acordo com aspectos da nova situação, que se assemelham à situação já encontrada.

Por sua vez, os cognitivistas acreditam que, mesmo no caso de haver toda a experiência possível com as diversas partes do problema, isso não garante que a solução do problema seja alcançada. O indivíduo é capaz de solucionar um problema se este for apresentado de um modo, mas não de outro, mesmo que ambas as formas requeiram as mesmas experiências passadas para serem solucionadas.

No entendimento dos cognitivistas, o método de apresentação do problema permite uma estrutura perceptual que leva ao insight, ou seja, à compreensão interna das relações essenciais do caso em questão.

A abordagem cognitivista ainda diferencia o processo de aprendizagem em dois modos distintos: aprendizagem mecânica e aprendizagem significativa. A aprendizagem mecânica está relacionada à aprendizagem de novas informações com pouca ou nenhuma associação com conceitos já existentes na estrutura cognitiva. A aprendizagem significativa processa-se quando um novo conteúdo (ideias ou informações) se relaciona com conceitos relevantes, claros e disponíveis na estrutura cognitiva, sendo, assim, assimilado por ela. Estes conceitos disponíveis compreendem os pontos de ancoragem para a aprendizagem.

De acordo com Bock (2002), os pontos de ancoragem são formados por intermédio da incorporação, à estrutura cognitiva de elementos relevantes (ideias ou informações) para a aquisição de novos conhecimentos e com a organização destes, de modo a, de forma progressiva, generalizarem-se formando conceitos.

Em suma, reputa-se que as diferentes teorias de aprendizagem desenvolvidas pela Psicologia procuram explicar esse processo a partir de visões divergentes. Atualmente, avultam, nas precípuas referências acerca da aprendizagem, as doutrinações de Vigotski e Piaget.

\section{PSICOLOGIA DA EDUCAÇÃO NA FORMAÇÃO DO EDUCADOR}

Para que o educador possa compreender o desenvolvimento do processo de aprendizagem no educando é de fundamental importância que ele tenha uma formação adequada na área da psicologia educacional. Somente com base nos conhecimentos 
acerca da relação que é construída na aprendizagem é que o educador poderá compreender o educando nas situações de dificuldade (ZUCOLOTTO, 2018).

Ensinar é, ao mesmo tempo, uma arte e uma ciência, argumenta Woolfolk (2000). O ensino eficiente e eficaz pressupõe uma compreensão dos achados de pesquisa sobre a aprendizagem e a instrução, bem como conhecimento de técnicas e rotinas eficazes. Ensinar também demanda a criatividade, o talento e o julgamento de um artista.

Deste modo, aprender e ensinar compreende um processo que se dá de forma gradativa. As preocupações e os problemas dos educadores mudam à medida que eles progridem.

Tornar-se um bom professor requer, desta forma, o estudo da psicologia educacional, sendo que o mesmo deve ser um bom aprendiz. A psicologia educacional auxilia o professor a lidar com uma gama ampla de capacidades e desafios que são propostos dentro do contexto escolar, pois cada aluno tem uma vida pessoal e necessidades diferentes.

Mediante o exposto, quando o educador navegar pelo material acadêmico, deve, ao mesmo tempo, cuidar das necessidades emocionais de seus alunos, levantando a autoestima baixa e incentivando a responsabilidade. Essa forma de ensino responsável só possível por meio do estudo da psicologia educacional.

No entendimento de Woolfolk (2000), os educadores especialistas, que fazem uso da psicologia educacional, têm sistemas de conhecimento elaborados para compreender os problemas de ensino.

Assim, por exemplo, quando um professor iniciante se depara com respostas erradas de alunos em provas de matemática ou história, todas as respostas erradas podem parecer igualmente erradas. Porém, um professor especialista reconhece que tais erros fazem parte de um sistema rico de conhecimento que pode incluir saber reconhecer diversos tipos de respostas erradas ou mal-entendimento ou falta de informação por trás de cada tipo de erro, sendo a melhor forma de ensinar novamente e corrigir malentendidos e verificar materiais e atividades que funcionaram no passado, bem como diversos modos de testar se a nova apresentação da matéria teve sucesso.

Neste sentido, Peterson e Comeaux (apud WOOLFOLK, 2000) sustentam que é a qualidade do conhecimento profissional dos professores e sua capacidade de estarem cientes de seu próprio pensamento que os torna mais aptos a ensinar. Um professor 
especialista tem profundo conhecimento da matéria acadêmica que ensina, sendo que desenvolve estratégias gerais de ensino que se aplicam a todas as matérias.

O educador especialista em educação ainda possui conhecimentos específicos da matéria, isto é, formas especiais de ensinar certos alunos e certos conceitos, tais como as melhores formas de explicar os números negativos para alunos de desempenho abaixo do considerado normal.

Além disso, a Psicologia da Educação envolve conteúdo e processo. Os achados de pesquisa garantem uma série de respostas possíveis a determinados problemas, e as teorias oferecem perspectivas para analisar quase todas as situações que possam surgir no contexto educacional.

Segundo Woolfolk (2000), como os pesquisadores identificaram uma série de técnicas eficazes de ensino, alguns educadores defendem que todos os professores devem aprender tais práticas e serem testados em relação a elas para obterem ou manterem suas habilitações para o magistério. Uma outra linha de pensamento argumenta que a marca de um excelente professor não é sua capacidade de aplicar técnicas, mas a arte de ser reflexivo - ponderado e inventivo - em relação ao ensino.

Entretanto, é importante ressaltar que, independentemente dessas duas visões, os professores necessitam ser, ao mesmo tempo, tecnicamente competentes e inventivos. Eles devem ser capazes de fazer uso de estratégias e também de inventar novas quando o contexto educacional exigir. Ao mesmo tempo em que o educador deve ter algumas rotinas simples que funcionem para o manejo das turmas, também deve estar disposto a quebrar a rotina quando a situação demandar modificações. Novos problemas surgem todo o tempo e, quando as velhas soluções não funcionam, é necessário implementar novas estratégias.

\section{CONSIDERAÇÕES FINAIS}

A Psicologia da Educação é um ramo da ciência voltado para o estudo das especificidades do campo da educação, devotando-se ao deslinde de problemas relacionados à educação, mormente aprendizagem, motivação e ajustamento escolar. Além disso, o psicólogo da área educacional desenvolve pesquisas descritivas, com base na observação e pesquisas experimentais, que possibilitem a formulação de princípios e, posteriormente, de teorias que possam orientar a atividade educativa. 
Todo o estudo da psicologia desenvolvido em torno do processo de educação tem o objetivo de propiciar a compreensão e o aperfeiçoamento dos processos de ensino e aprendizagem, fazendo uso dos conhecimentos e técnicas da Psicologia Geral, mas, entrementes, desenvolvendo seus próprios conhecimentos e técnicas.

Contudo, a Psicologia da Educação exige a formação de educadores de forma adequada. É necessário que estes tenham conhecimentos teóricos acerca de como ocorre o processo de aprendizagem nos indivíduos e conheçam seus alunos para que possam se orientar pelas teorias existentes e aplicar aquilo que é conveniente em cada contexto educacional.

Somente a partir do conhecimento sobre como se constrói a aprendizagem para o aluno é que o educador poderá compreender o educando nas situações de dificuldade, sendo capaz de interferir no processo e propor formas de educação que se ajustem àquele indivíduo. Assim é possível observar que a psicologia educacional, com suas teorias já desenvolvidas, contribui de forma substancial na resolução de problemas que dizem respeito à educação e a aprendizagem.

Cumpre destacar que se tornar um educador especializado em Psicologia da Educação requer tempo e experiência, porquanto o docente necessita de conjunto de conhecimentos bem organizados sobre as diferentes situações específicas do ensino. Isso envolve conhecimentos acerca das matérias que ensinam, de seus alunos, estratégias gerais de ensino, formas específicas de ensinar cada matéria, entre outros conhecimentos.

Pode-se ressaltar, igualmente, que um dos mais complexos temas relacionados à Psicologia da Educação que ainda prevalece na aprendizagem e no ensino é a questão da motivação. Motivar o aluno e um dos principais desafios que se impõe diante da atividade desenvolvida pelo educador. Assim, para amenizar este problema, o educador precisa estar atento às necessidades do aluno, buscando associar a tais necessidades outros conteúdos. Pode, também, criar outros interesses no aluno, propiciando-lhe descobrir e desenvolvendo nele uma atitude de investigação.

\section{REFERÊNCIAS BIBLIOGRÁFICAS}

ALENCAR, Eunice M. L. Soriano de. Psicologia: introdução aos princípios básicos comportamentais. Petrópolis:Vozes, 1983.

BOCK, Ana Mercês Bahia et al. Psicologias: uma introdução ao estudo de psicologia. 13. ed. reform. e ampl. São Paulo: Saraiva, 2002. 
CRUZ, Murilo Galvão Amancio. A defesa de uma atitude na psicologia: breve reflexão sobre a prática psi e o processo de medicalização. Revista Filogênese - Revista Eletrônica de Pesquisa na Graduação em Filosofia da UNESP. Vol. 6, nº 1, 2013. Disponível em:

https://www.marilia.unesp.br/Home/RevistasEletronicas/FILOGENESE/murilocruz.pdf Acesso em: 19 ago. 2019.

FALCÃO, Gérson Marinho. Psicologia da aprendizagem. São Paulo: Ática, 1984.

FONTOURA, Amaral. Psicologia Educacional. 22. ed. Rio de Janeiro: Aurora, 1973.

HOLANDA, Adriano Furtado. "O Que é Psicologia?": Dilemas Epistemológicos e Repercussões Contemporâneas. Revista de Psicologia. v. 10 n. 1 (2019): Edição Especial(jan-jun): A(s) Psicologia(s) e suas Indisciplinas: epistemologias, éticas e políticas. Disponível em: http://www.periodicos.ufc.br/psicologiaufc/article/view/33638 Acesso em: 18 ago. 2019.

MAYER, Rosana. Proposta Metodológica de Empreendedorismo no Ensino Média: uma aplicação no CEFET-PR. 2001. Dissertação (Mestrado em Engenharia de Produção) - Universidade Federal de Santa Catarina, Florianópolis, 2001. Disponível em: https://repositorio.ufsc.br/xmlui/handle/123456789/81637 Acesso em: 20 ago. 2019.

NOVAES, Maria Helena. Psicologia do ensino-aprendizagem. São Paulo: Atlas, 1977.

PILETTI, Nelson. Psicologia educacional. São Paulo: Ática, 1985.

TELES, Antônio Xavier. Psicologia moderna. 11. ed. São Paulo: Ática, 1974.

TELES, Maria Luisa S. O que é psicologia. São Paulo: Brasiliense, 1999.

TOURINHO, Emmanuel Zagury; NETO, Marcus Bentes de Carvalho; NENO, Simone Neno. A Psicologia como campo de conhecimento e como profissão de ajuda. Estudos de Psicologia 2004, 9(1), 17-24. Disponível em:

http://www.scielo.br/pdf/epsic/v9n1/22377.pdf Acesso em: 17 ago. 2019.

WOOLFOLK, Anita E. Psicologia da Educação. 7. ed. Porto Alegre: Artes Médicas Sul, 2000.

ZUCOLOTTO, Marcele Pereira da Rosa. Contribuições da psicologia à educação básica e o problema da psicologização da educação: uma revisão narrativa. Rev. HISTEDBR On-line, Campinas, v.18, n.4 [78], p.1195-1208, out./dez. 2018. Disponível em: https://periodicos.sbu.unicamp.br/ojs/index.php/histedbr/article/view/8652472 Acesso em: 20 ago. 2019.

\section{Credenciais da/os autora/es}


REGERT, Rodrigo. Professor e Coordenador de Curso Superior no Serviço Nacional de Aprendizagem Comercial (SENAC - Videira SC), tecnólogo em Processos Gerencias pela Faculdade Alfa América (FAA), licenciado em Filosofia pela Universidade de Caxias do Sul (UCS), máster em Educação pela Universidad Tecnológica Intercontinental (UTIC), mestre em Desenvolvimento e Sociedade pela Universidade Alto Vale do Rio do Peixe (UNIARP). E-mail:regert.rodrigo@ gmail.com.br

SANTOS, Adelcio Machado dos. Docente e pesquisador da UNIARP, nos Programas de Pós-Graduação "Stricto Sensu” em Desenvolvimento e Sociedade e Educação, graduado em Direito pela Universidade do Vale do Itajaí (UNIVALI), licencidado em Filosofia pela Universidade do Sul de Santa Catarina (UNISUL), mestre em Relações Internacionais (UNISUL), doutror em Engenharia e Gestão do Conhecimento pela Universidad Federal de Santa Catarina (UFSC). E-mail: adelciomachado@ gmail.com.br.

Endereço para correspondência: Rodrigo Regert. Avenida Idamir Bogoni n538, Bairro Das Nações, 89.580-000.

Como citar este artigo (Formato ABNT): REGERT, Rodrigo; SANTOS, Adelcio Machado dos. Psicologia da Educação: Análise do Estatuto Espistemológico. Educação, Psicologia e Interfaces, v. 3, n.3, p. 107-121, 2019. DOI: https://doi.org/10.37444/issn2594-5343.v3i3.160

Recebido: 07/08/2019.

Aceito: 20/11/2019. 